\title{
WAVE3 upregulation in esophageal squamous cell carcinoma and its effect on the migration of human esophageal cancer cell lines in vitro
}

\author{
XUEBING LI*, JIE GENG*, ZHENZHEN REN, CHAO XIONG, YUQING LI and HONGCHUN LIU
}

Department of Medical Laboratory, First Affiliated Hospital of Zhengzhou University, Zhengzhou, Henan 450052, P.R. China

Received July 11, 2019; Accepted March 31, 2020

DOI: $10.3892 / \mathrm{mmr} .2020 .11126$

\begin{abstract}
The present study aimed to investigate the role of Wiskott-Aldrich syndrome verprolin-homologous protein 3 (WAVE3) in the progression of esophageal squamous cell carcinoma (ESCC), and to explore its effect on the migration of esophageal cancer cell lines in vitro. The expression level of WAVE3 in ESCC tissues was determined via immunohistochemistry, and the relative levels of WAVE3 mRNA and micro (mi)RNA200b were assessed in the serum of patients with ESCC using reverse transcription-quantitative PCR (RT-qPCR). Following cell transfection, the levels of miRNA200b and WAVE3 protein were determined via RT-qPCR and western blot analysis, and cell migration was examined using a Transwell assay. Subsequently, the clinical parameters were used to analyze whether the expression of WAVE3 in tissues and serum was associated with the occurrence and development of ESCC. The results demonstrated that the expression of WAVE3 was increased in ESCC tissues compared with normal tissues. The results also revealed increased expression levels of WAVE3 and decreased expression levels of miRNA200b in the serum of patients with ESCC, compared with healthy volunteers. High expression of WAVE3 was significantly associated with tumor TNM stage, invasion depth and lymphatic invasion of ESCC. In cells transfected with miRNA200b mimic, the miRNA200b was overexpressed, WAVE3 protein was downregulated and cell migration ability was decreased. The results of the present study suggest that WAVE3 may serve as an oncogene in ESCC, and its inhibition via miRNA200b decreased tumor cell
\end{abstract}

Correspondence to: Professor Hongchun Liu, Department of Medical Laboratory, First Affiliated Hospital of Zhengzhou University, 1 Jianshe East Road, Wulibao Street, Erqi, Zhengzhou, Henan 450052, P.R. China

E-mail: xingyunerliu@163.com

${ }^{*}$ Contributed equally

Key words: esophageal squamous cell carcinoma, Wiskott-Aldrich syndrome verprolin-homologous protein 3 , microRNA200b, migration, biomarkers migration. Therefore, WAVE3 may serve as a novel biological marker and therapeutic target for ESCC.

\section{Introduction}

Esophageal cancer (EC) is one of the most common malignant tumors of the digestive system worldwide based on the statistical analysis of 2008 (1). Although its degree of malignancy is inferior to gastric and liver cancer, according to statistics from the National Cancer Center in 2017, EC ranks as the fourth most common cause of malignant tumor-associated mortality in China (1-3). There are two main types of EC, esophageal squamous cell carcinoma (ESCC), which accounts for $>90 \%$ of cases, and esophageal adenocarcinoma $(4,5)$. At present, the primary treatment strategy for EC involves surgery, radiotherapy and chemotherapy, and the main causes of mortality are recurrence and metastasis (6). Patients with EC typically have a 5-year survival rate of 20-25\%, even after radical resection, which is caused by $>90 \%$ of patients with EC being diagnosed at the advanced stages, when the available treatment strategies are no longer optimal $(7,8)$. Additionally, early diagnostic techniques used for EC, including X-ray angiography, exfoliative cytology and endoscopy, have complicated clinical operations and are often inaccurate; therefore, the techniques cannot be used for routine screening $(6,9-11)$. With the continuous development of molecular tumor markers, the detection, simplicity, effectiveness and reliability of using peripheral blood serum has aided in the early diagnosis and treatment of patients with tumors $(12,13)$. However, the current markers for the early diagnosis and treatment of EC are in the early stages of research and further investigation is required to identify additional specific molecular biomarkers.

The Wiskott-Aldrich syndrome protein (WASP) family consists of novel actin-regulating proteins, which serve a regulatory role in cell structure, cell membrane actin polymerization regulation, cell migration and movement (14-16). Previous studies have indicated that WASP deficiencies can result in abnormal maintenance of morphological structure and cell migration $(17,18)$. As an important member of the WASP family, Wiskott-Aldrich syndrome verprolin-homologous protein 3 (WAVE3) is a proline-rich protein, which influences cell migration, the maintenance of cell structure and the regulation of actin polymerization $(19,20)$. A number of studies have demonstrated the role of WAVE3 during tumor cell migration and 
invasion $(21,22)$. Davuluri et al $(23,24)$ reported that WAVE3 was associated with a variety of signaling pathways, and cell migration regulation involved the NF- $\kappa \mathrm{B}$ signaling pathway. Further studies have indicated that WAVE3 affects proliferation, migration and invasion abilities in pancreatic cancer cells via the AKT signaling pathway, suggesting that the targeted inhibition of WAVE3 expression may serve as a novel therapeutic strategy for pancreatic cancer $(25,26)$. Therefore, WAVE3, as a potential tumor marker, and may have broad application prospects for the diagnosis, prognosis and treatment of a number of different tumors (27). WAVE3 expression is upregulated in pancreatic cancer $(25,26)$ and breast cancer cells, particularly in triple-negative breast cancer $(27,28)$ and human prostate cancer (29). Numerous studies have investigated the roles of WAVE3, including its effect on cell motility, migration and invasion, in a number of different types of cancer, including hepatocellular carcinoma, prostate cancer and colorectal cancer $(22,29,30)$. However, the expression of WAVE3 in EC and the associated underlying mechanisms are yet to be fully elucidated.

MicroRNAs (miRNAs/miRs) are endogenous non-coding RNAs which bind the 3'-untranslated regions (3'-UTR) of mRNAs to regulate gene expression (31). The miRNA-200 family includes three members: miR200a, miR200b and miR200c. Sossey-Alaoui et al (32) demonstrated that miRNA200 binds to the 3'-UTR of WAVE3 to inhibit WAVE3 protein expression and influence the progression of tumors, with miRNA200b being identified as the representative member. The present study aimed to regulate the expression of WAVE3 using miRNA200b, and to further explore the effect of WAVE3 on cell migration ability in ESCC. Previous studies have indicated that WAVE3 is associated with alterations to cell motility via the epithelial-mesenchymal transition (EMT) process $(21,33-35)$, which is important during wound healing, embryonic development, and cell migration and invasion (36). A number of studies have also demonstrated that miRNA200 is associated with the regulation of EMT, via the regulation of WAVE3 protein $(30,32,37)$. However, the mechanisms underlying the actions of WAVE3 in ESCC require further investigation.

In the present study, the expression level of WAVE3 in ESCC tissues and serum, and its association with the progression of ESCC was determined. miRNA200b mimics were transfected into ESCC cell lines (EC109 and EC1), and the negative regulation of WAVE3 expression via miRNA200b was investigated. The present study provided novel insight into the progression of ESCC and identified a potential diagnostic biomarker and therapeutic target for ESCC.

\section{Materials and methods}

Tissue samples and peripheral blood collection. A total of 62 pairs of ESCC tissue samples and corresponding adjacent normal tissues were collected between September 2017 and December 2017 from the Pathology Laboratory of the First Affiliated Hospital of Zhengzhou University (Zhengzhou, China). A total of 80 patients with ESCC and 30 healthy volunteers were enrolled between January 2018 and March 2018 from the Clinical Laboratory of the First Affiliated Hospital of Zhengzhou University (Zhengzhou, China). Serum samples were collected from patients and healthy volunteers. The mean age of patients and volunteers was 60 years, ranging 37-75 years. The female-to-male ratio of tissue samples was 0.7 , and 0.5 in serum samples (Tables I and II). All samples were centrifuged at $1,370 \mathrm{x}$ g for $5 \mathrm{~min}$ at $4^{\circ} \mathrm{C}$ to extract serum within $2 \mathrm{~h}$ of collection, again at $16,000 \mathrm{xg}$ for $5 \mathrm{~min}$ at $4^{\circ} \mathrm{C}$ to completely remove cell debris and subsequently stored at $-80^{\circ} \mathrm{C}$ until RNA extraction. Tissue samples had not received anticancer treatment prior to routine surgical resection, and all samples were confirmed as ESCC via pathological analysis by two independent pathologists blind to the clinical details of the patients. Serum samples were obtained at the time of primary diagnosis, before treatment, by collecting venous blood. The basic clinicopathological parameters of the patients are presented in Tables I and II. The tumor staging was assessed according to the TNM stage (38). The present study was approved by the Institute Research Ethics Committee of the First Affiliated Hospital of Zhengzhou University. All patients provided written informed consent.

Immunohistochemical (IHC) staining. The patient tissue samples (paraffin sections of $4 \mu \mathrm{m}$ fixed using $4 \%$ paraformaldehyde for $48 \mathrm{~h}$ at room temperature) were used for IHC staining. For antigen retrieval, all paraffin sections that had been deparaffinized in xylene for $15 \mathrm{~min}$, were rehydrated with a descending alcohol series (100, 95, 90, 75 and 70\%) for 3 min each. stage, and treated with EDTA buffer in a microwave for $10 \mathrm{~min}$. Subsequently, the slides were treated with 3\% hydrogen peroxide to inhibit endogenous peroxidase activity and $10 \%$ goat serum (Sangon Biotech Co., Ltd.) was used to block non-specific binding sites for $30 \mathrm{~min}$ at room temperature. The sections were incubated overnight at $4^{\circ} \mathrm{C}$ with the anti-WAVE3 primary antibody (1:400, cat. no. 2806S; Cell Signaling Technology, Inc.), followed by incubation for $20 \mathrm{~min}$ at room temperature with a HRP-conjugated goat anti-rabbit secondary antibody (1:100, cat. no. A0208, Beyotime Institute of Biotechnology). Chromogen detection was performed using 3,3'-diaminobenzidine. Following counterstaining with hematoxylin for $3 \mathrm{~min}$ at room temperature, dehydrated (descending alcohol series: 70, 75, 90, 95 and 100\% for $1 \mathrm{~min}$ each, xylene for $15 \mathrm{~min}$, all at room temperature), and coverslipped with neutral gum,, sections were observed under a light microscope (magnification, x100) by two pathologists from the Pathology Laboratory of the First Affiliated Hospital of Zhengzhou University (Zhengzhou, China). The two had no knowledge of the clinical data prior to evaluation were specialized in diagnosing of ESCC. In the event of disagreement or difficulty, a third pathologist was asked. Both intensity and extent were considered using Image J (version 1.8.0; National Institutes of Health). Intensity was scored from 0 to 3 and extent was scored from 0 to $100 \%$. The score of intensity was defined: No positive staining $=0$, light yellow $=1$, yellow-brown $=2$ and brown $=3$. For the area of positive staining: No positive staining $=0,30 \%$ positive staining $=1,30-60 \%$ positive staining $=2$ and $>60 \%$ positive staining $=3$. Final quantitation of staining was calculated by multiplying the intensity and extent scores. Sections with scores $>1.5$ were considered as WAVE3-positive and sections were scores $\leq 1.5$ were considered as WAVE3-negative.

Cell culture and mimics transfection. Human ESCC cell lines (EC109 and EC1) were obtained from Basic Medical College of 
Table I. Association between clinicopathologic parameters and WAVE3 expression.

WAVE3 expression

\begin{tabular}{|c|c|c|c|c|}
\hline \multirow[b]{2}{*}{ Clinicopathologic parameter } & \multirow[b]{2}{*}{ Patients (n) } & & \multirow[b]{2}{*}{ P-value } \\
\hline & & High, n (\%) $(\mathrm{n}=13)$ & Low, n $(\%)(n=49)$ & \\
\hline Sex & & & & 0.775 \\
\hline Male & 36 & $8(22.2)$ & $28(77.8)$ & \\
\hline Female & 26 & $5(19.2)$ & $21(80.8)$ & \\
\hline Age & & & & 0.565 \\
\hline$<60$ years & 29 & $7(24.1)$ & $22(75.9)$ & \\
\hline$\geq 60$ years & 33 & $6(18.2)$ & $27(81.8)$ & \\
\hline TNM stage & & & & $0.027^{\mathrm{a}}$ \\
\hline $\mathrm{I} / \mathrm{II}$ & 40 & $5(12.5)$ & $35(87.5)$ & \\
\hline III/IV & 22 & $8(36.4)$ & $14(63.6)$ & \\
\hline Infiltrate depth & & & & $0.027^{\mathrm{a}}$ \\
\hline Submucosal/superficial layer & 15 & $0(0)^{\mathrm{b}}$ & $15(100.0)$ & \\
\hline Deep muscle/outer layer & 47 & $13(27.7)$ & $34(72.3)$ & \\
\hline Lymphatic invasion & & & & $0.002^{\mathrm{a}}$ \\
\hline Positive & 21 & $9(42.9)$ & $12(57.1)$ & \\
\hline Negative & 41 & $4(9.8)$ & $37(90.2)$ & \\
\hline
\end{tabular}

${ }^{\mathrm{a}} \mathrm{P}<0.05 .{ }^{\mathrm{b}}$ Fisher's Exact Test: $\mathrm{n}<1$. WAVE3, Wiskott-Aldrich syndrome verprolin-homologous protein 3 .

Table II. Association between WAVE3 mRNA expression in serum and clinicopathologic parameters.

\begin{tabular}{|c|c|c|c|c|}
\hline \multirow{2}{*}{$\begin{array}{l}\text { Clinicopathologic } \\
\text { parameter }\end{array}$} & \multirow[b]{2}{*}{ Samples (n) } & \multicolumn{2}{|c|}{$\begin{array}{c}\text { WAVE3 } \\
\text { mRNA } \\
\text { expression }\end{array}$} & \multirow[b]{2}{*}{ P-value } \\
\hline & & High & Low & \\
\hline Sex & & & & 0.398 \\
\hline Male & 55 & 48 & 7 & \\
\hline Female & 25 & 20 & 5 & \\
\hline Age, years & & & & 0.803 \\
\hline$<60$ & 21 & 17 & $4^{b}$ & \\
\hline$\geq 60$ & 59 & 51 & 8 & \\
\hline TNM stage & & & & $0.012^{\mathrm{a}}$ \\
\hline I/II & 40 & 21 & 19 & \\
\hline III/IV & 28 & 23 & 5 & \\
\hline Lymphatic invasion & & & & $0.026^{\mathrm{a}}$ \\
\hline Yes & 22 & 19 & $3^{\mathrm{b}}$ & \\
\hline No & 45 & 25 & 20 & \\
\hline
\end{tabular}

${ }^{\mathrm{a}} \mathrm{P}<0.05$. ${ }^{\mathrm{b}}$ Continuity correction: $1<\mathrm{n} \leq 5$. WAVE3, Wiskott-Aldrich syndrome verprolin-homologous protein 3 .

Zhengzhou University which had purchased the cell lines from Shanghai Institute of Life Sciences cell bank center (Shanghai, China). Cells were cultured in RPMI-1640 medium (Sangon Biotech Co., Ltd.) supplemented with 10\% FBS (Sangon
Biotech Co., Ltd.) and maintained at $37^{\circ} \mathrm{C}$ with $5 \% \mathrm{CO}_{2}$. Cells were passaged every 2 days to maintain logarithmic growth until further analysis. The mature miRNA200b sequence (access no. MIMAT0000318) and the putative miRNAs that target WAVE3 was obtained from the miRBase database (version 22; http://www.mirbase.org). miRNA200b mimic (5'-UAAUACUGCCUGGUAAUGAUGA-3') and mimic scrambled negative control (access no. MIMAT0000295; 5'-UUUGUACUACACAAAAGUACUG-3') were synthesized by Guangzhou Ribobio Co., Ltd. Mimics and mimic negative controls were diluted with riboFECT ${ }^{\mathrm{TM}}$ CPBuffer according to the manufacturer's protocol (Guangzhou RiboBio Co., Ltd.) and incubated for $15 \mathrm{~min}$ at room temperature. Subsequently, mimics and mimic negative controls (final concentration $50 \mathrm{nM})$ were transfected to the cells $\left(4 \times 10^{5} /\right.$ well in a 6 -well plate) with riboFECT ${ }^{\text {тм }}$ CPReagent according to the manufacturer's protocol (Guangzhou Ribobio Co., Ltd.) at $37^{\circ} \mathrm{C}$ with $5 \% \mathrm{CO}_{2}$ for 24 to $96 \mathrm{~h}$. The control group received no treatment. After transfection for 48 or $72 \mathrm{~h}$, cells were collected for the later RNA extraction and Transwell assay or western blotting.

$R N A$ extraction and reverse transcription-quantitative $P C R$ (RT-qPCR). Total RNA was extracted from serum and transfected cells with mimics and mimic negative controls using RNA isoBlood reagent (Takara Biotechnology Co., Ltd.), according to the manufacturer's protocol. Total RNA was reverse transcribed into cDNA using the PrimeScript Reverse Transcription kit according to the manufacturer's protocol (Takara Biotechnology Co., Ltd.). Subsequently, qPCR was performed using the TB Green Premix Taq II reagent kit according to the manufacturer's protocol (Takara 
Biotechnology Co., Ltd.) to quantify WAVE3 mRNA in serum and miRNA200b in serum and RNA extracted from transfected cells on a LightCycler 480 II Real-Time PCR System (Roche Diagnostics). The thermocycling conditions were: Pre-denaturation at $95^{\circ} \mathrm{C} 30 \mathrm{sec}$ for 1 cycle, then $95^{\circ} \mathrm{C}$ for $5 \mathrm{sec}, 60^{\circ} \mathrm{C}$ for $20 \mathrm{sec}$ for 40 cycles and followed by the melting curve and cooling stage at $65^{\circ} \mathrm{C}$ for $15 \mathrm{sec}$. RNA levels were calculated using $2^{-\Delta \Delta C q}$ method (39). Patients with ESCC were classified into two groups (high and low expression) according to the mean value of serum WAVE3 expression in patients with ESCC. The following primer pairs were used for qPCR: WAVE3 forward, 5'-GTGACGGTAGGAATGTGAGCA-3' and reverse, 5'-CAAGCCCAACAGGTAGCCA-3'; GAPDH forward, 5'-GAACGGGAAGCTCACTGG-3' and reverse, 5'-GCCTGCTTCACCACCTTCT-3'; and U6 forward, 5'-CTC GCTTCGGCAGCACA-3' and reverse, 5'-AACGCTTCACGA ATTTGCGT-3'. The primers of miRNA200b were synthesized by Guangzhou Ribobio Co., Ltd. And the sequences are proprietary. mRNA and miRNA expression levels were normalized to the internal reference genes GAPDH and U6, respectively.

Western blot analysis. Total protein was extracted from cells transfected with mimics and mimic negative controls using RIPA lysis buffer (Sangon Biotech Co., Ltd.) and quantified using a bicinchoninic acid protein assay kit (Sangon Biotech Co., Ltd.), according to the manufacturer's protocol. Subsequently, proteins $(25 \mu \mathrm{g} /$ lane $)$ were separated via $12 \%$ SDS-PAGE and transferred onto PDVF membranes. After blocking with $5 \%$ non-fat dry milk for $2 \mathrm{~h}$ at room temperature, the membranes were incubated with the anti-WAVE3 primary antibody (1:1,000, cat. no. 2806S; Cell Signaling Technology, Danvers, Inc.) and anti-GAPDH primary antibody (1:6,000, cat. no. G8795; Sigma-Aldrich; Merck KGaA), overnight at $4^{\circ} \mathrm{C}$. Subsequently, the membranes were washed with TBST and incubated with the HRP-conjugated goat anti-rabbit secondary antibody (1:1,000, A0208, Beyotime Institute of Biotechnology) for $2 \mathrm{~h}$ at room temperature. Protein band images were visualized with an ECL kit (Sangon Biotech Co., Ltd.) and captured using a chemiluminescence imaging system (EMD Millipore) and then analyzed with ImageJ (version 1.8.0; National Institutes of Health). GAPDH was used as the loading control.

Cell migration assay. Transwell plates (24-well; pore diameter, $0.8 \mu \mathrm{m}$ ) were used to determine the cell migration ability. miRNA200b mimic transfected cells $\left(5 \times 10^{5}\right.$ cells $\left./ \mathrm{ml}\right)$ were plated into the top chambers of the Transwell plates with RPMI-1640 medium. RPMI-1640 medium containing 20\% goat serum was plated into the lower chambers as a chemoattractant. The Transwell plates were incubated for $36 \mathrm{~h}$ at $37^{\circ} \mathrm{C}$ with $5 \%$ $\mathrm{CO}_{2}$. Subsequently, non-migrated cells on the upper surface of the Transwell membrane were removed using a cotton swab. After fixing with $4 \%$ paraformaldehyde for $10 \mathrm{~min}$ at room temperature, migrating cells were stained with gentian violet for $30 \mathrm{~min}$ at room temperature. Stained cells were visualized under a light microscope (magnification, x100).

Statistical analysis. Statistical analyses were performed using SPSS (version 21.0; IBM Corp.), GraphPad Prism (version 6;
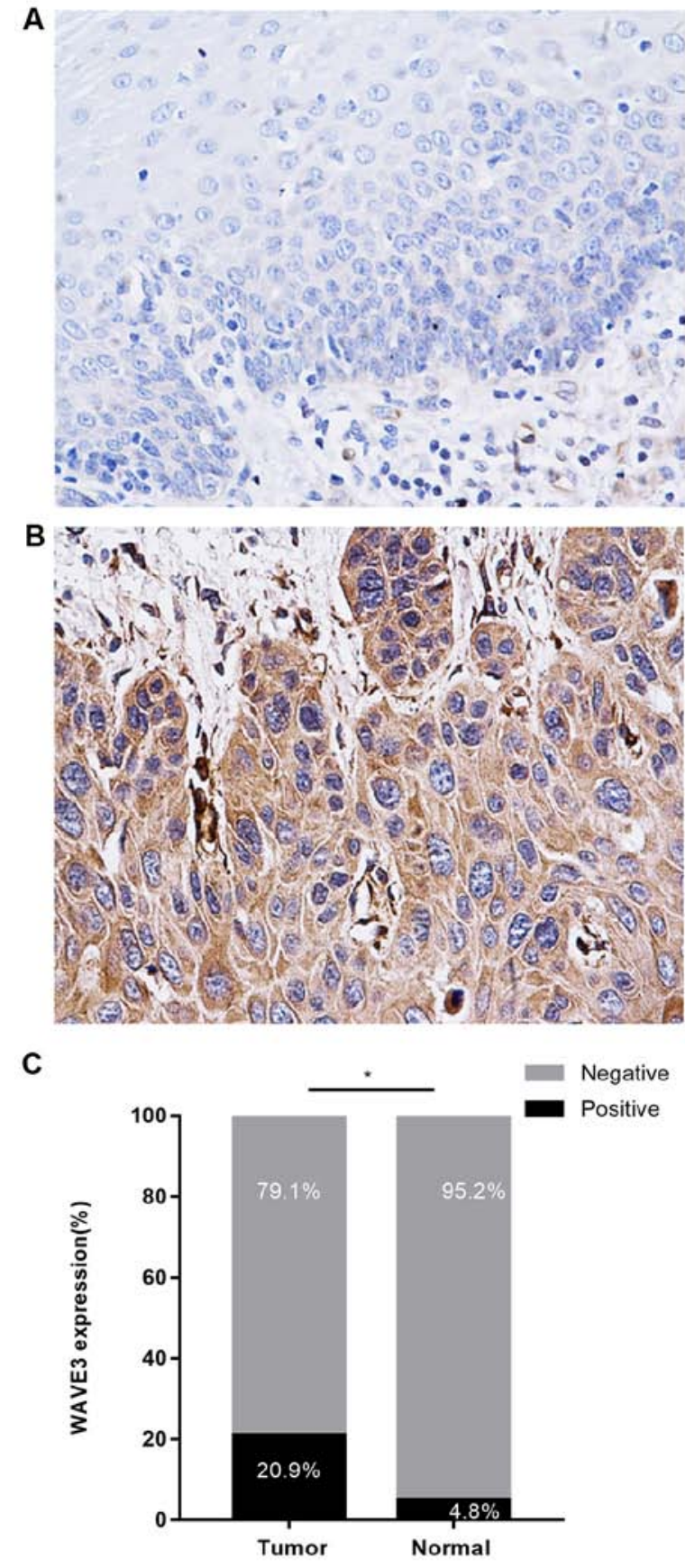

Figure 1. Immunohistochemical staining of WAVE3 in ESCC tissues and adjacent normal tissues. (A) Low WAVE3 expression in adjacent normal tissues (magnification, x100). (B) High WAVE3 expression in ESCC tissues (magnification, $\mathrm{x} 100$ ). (C) WAVE3 expression levels were compared between ESCC tissues and adjacent normal tissues. ${ }^{*} \mathrm{P}<0.05$. WAVE3, Wiskott-Aldrich syndrome verprolin-homologous protein 3; ESCC, esophageal squamous cell carcinoma.

GraphPad Software, Inc.) and Image J (version 1.8.0; National Institutes of Health) software. Receiver operating characteristic curves were constructed and the area under the curve (AUC) was analyzed to evaluate the diagnostic value of serum WAVE3 expression levels in ESCC. Normally distributed data are presented as the mean \pm standard deviation and non-normally distributed data are expressed as the median and interquartile range. WAVE3 expression levels between paired tumor and corresponding adjacent normal tissues was compared using 
A

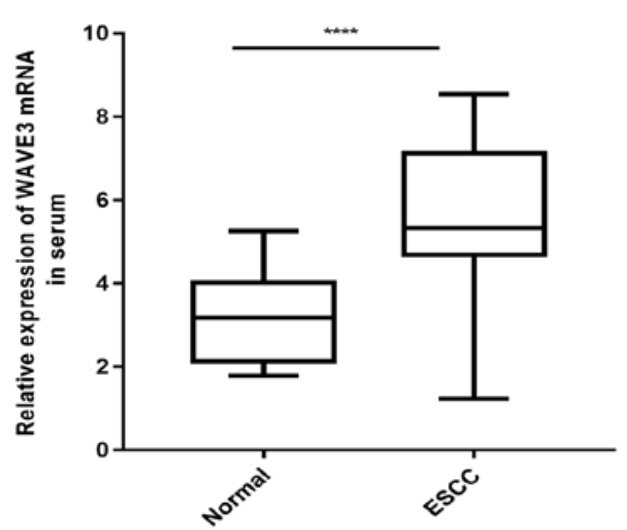

$\mathbf{B}$

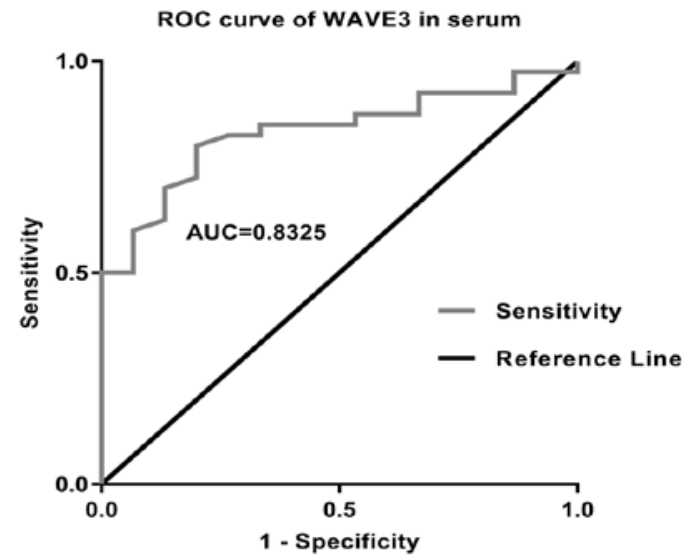

Figure 2. WAVE3 is upregulated in ESCC serum. (A) Relative expression of WAVE3 mRNA in serum of patients with ESCC and healthy volunteers. (B) ROC curve of WAVE3 in serum (AUC $=0.83251 ; \mathrm{P}<0.001) .{ }^{* * * *} \mathrm{P}<0.0001$. WAVE3, Wiskott-Aldrich syndrome verprolin-homologous protein 3 ; ESCC, esophageal squamous cell carcinoma; ROC, receiver operating curve; AUC, area under the curve.

the paired Student's t-test. Data containing two independent groups were compared using an unpaired Student's t-test. Data containing $>2$ groups were compared using one-way ANOVA followed by the LSD post hoc test. Pearson's $\chi^{2}$ test was used to analyze the association between WAVE3 expression and clinicopathologic characteristics; however, when the number of cases was $<5$, continuity correction and Fisher's Exact Test were used. $\mathrm{P}<0.05$ was considered to indicate a statistically significant difference.

\section{Results}

IHC analysis of the expression of WAVE3 protein in ESCC, and its association with clinical parameters. According to the immunohistochemical staining assay, WAVE3 expression was primarily localized in the cytoplasm of ESCC cells, and the expression of WAVE3 was increased in ESCC tissues compared with normal tissues (Fig. 1A and B). WAVE3-positive staining in ESCC tissues (20.9\%) was significantly higher compared with paired normal tissues $(4.8 \%$; $\mathrm{P}<0.05$; Fig. $1 \mathrm{C})$. The present study also assessed the association between WAVE3 protein expression and clinicopathologic variables of patients with ESCC. Increased WAVE3 expression was associated with TNM stage $(\mathrm{P}=0.027)$, infiltrate depth $(\mathrm{P}=0.027)$ and lymphatic invasion $(\mathrm{P}=0.002)$ (Table I). However, no significant association was identified between WAVE3 expression and patient sex or age ( $\mathrm{P}>0.05$; Table I).

WAVE3 mRNA expression in serum and its association with clinical parameters. WAVE3 mRNA expression levels in the serum of patients with ESCC were determined via RT-qPCR (Fig. 2A). The results indicated that WAVE3 expression was upregulated in serum of patients with ESCC compared with healthy donors [5.3250; interquartile range (IQR), 4.6825-7.1225 vs. 3.1800; IQR, 2.1300-4.0200], which supported the results of the IHC staining assay. As shown in Fig. 2B, the AUC of WAVE3 was 0.8325 [95\% confidence interval (CI); 0.7249-0.9401], which indicated that WAVE3 exhibited a good diagnostic performance. Subsequently, the association between the WAVE3 mRNA expression levels in serum and clinicopathological features was assessed. High
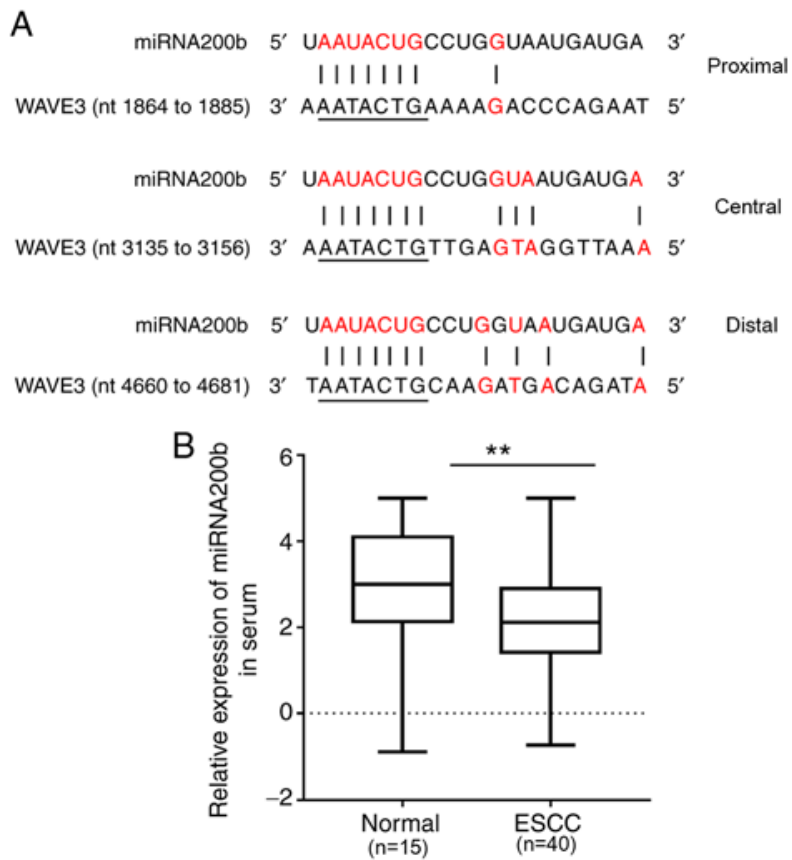

Figure 3. miRNA200b expression in ESCC serum. (A) Three different locations in the 3'-UTR of the WAVE3 gene that interact with miR200b. (B) Relative expression of miRNA200b in the serum of patients with ESCC and healthy volunteers. ${ }^{* *} \mathrm{P}<0.01$, as indicated. miRNA, microRNA; ESCC, esophageal squamous cell carcinoma; WAVE3, Wiskott-Aldrich syndrome verprolin-homologous protein 3; nt, nucleotide.

expression of WAVE3 mRNA was associated with TNM stage $(\mathrm{P}<0.05)$ and lymphatic invasion $(\mathrm{P}<0.05)$ (Table II). However, there was no significant association between serum WAVE3 expression and patient sex or age $(\mathrm{P}>0.05$; Table II).

miRNA200b expression levels in serum and its association with WAVE3. MiRBase was also used to search the putative miRNAs that target WAVE3 $(40,41)$, and it was indicated that miRNA200b had three potential binding sites in the 3'-UTR of WAVE mRNA (Fig. 3A). miRNA200b expression levels were examined via RT-qPCR and the results suggested that the expression of miRNA200b in ESCC serum was significantly 
A

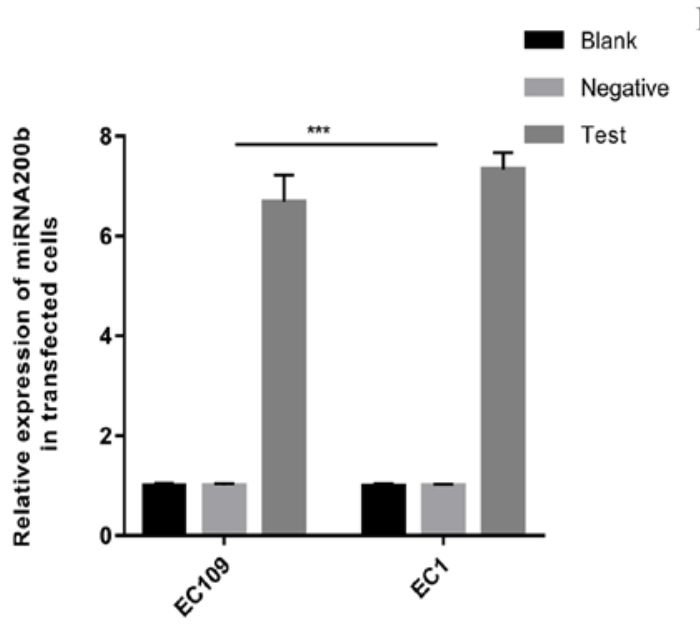

C

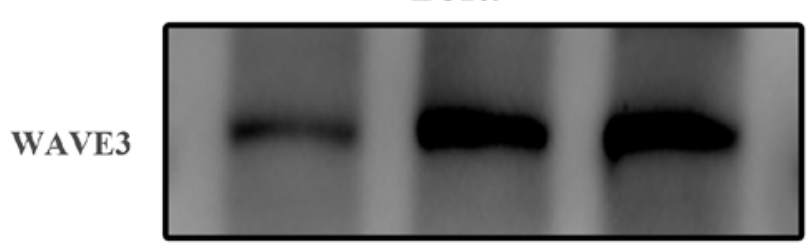

EC109

GAPDH

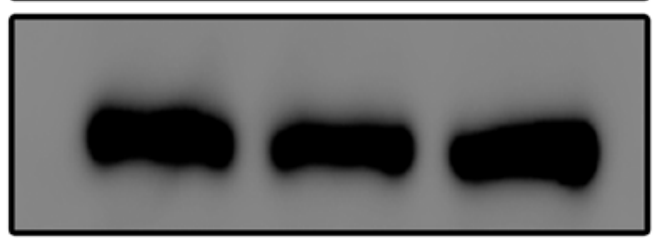

Test

Negative

Control
B

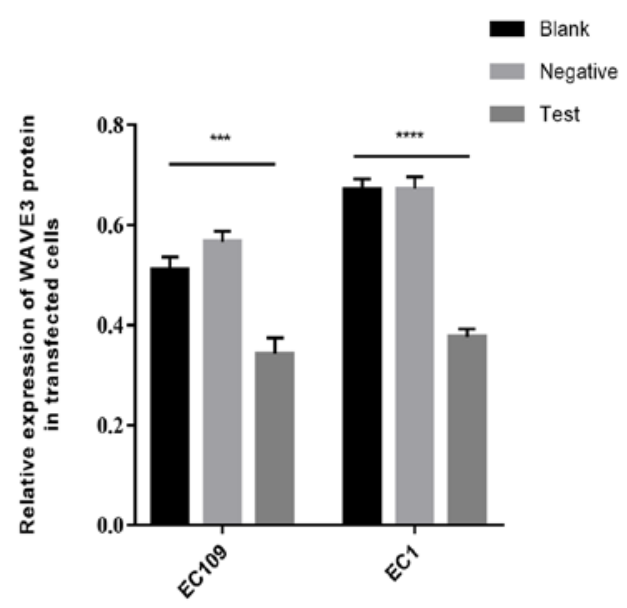

EC1
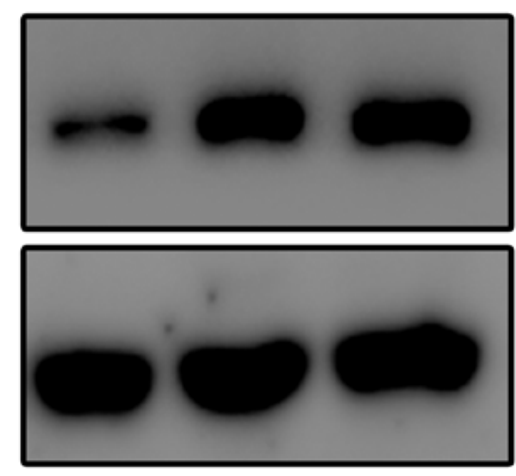

Test Negative Control

Figure 4. Transfection efficiency evaluated via western blotting. (A) Relative expression levels of miR200b in ESCC cell lines between blank group and cells transfected with miRNA200b mimic or mimic negative control. (B and C) Protein expression levels of WAVE3 in EC1 and EC109 cell lines between cells with nothing treatment and cells transfected with miRNA200b mimic or mimic negative control, as determined via western blotting. ${ }^{* * *} \mathrm{P}<0.001$ and ${ }^{* * * *} \mathrm{P}<0.0001$. miR/miRNA, miroRNA; ESCC, esophageal squamous cell carcinoma; WAVE3, Wiskott-Aldrich syndrome verprolin-homologous protein 3.

decreased compared with normal serum $(\mathrm{P}<0.0001$; Fig. $3 \mathrm{~B})$. Together with the increased level of WAVE3 in ESCC serum compared with the normal group, it was hypothesized that miRNA200b expression is negatively associated with WAVE3 expression.

WAVE3 expression is inhibited by miRNA200b in ESCC cell lines. To investigate whether miRNA200b alters the expression of WAVE3, EC109 and EC1 cell lines were transfected with miRNA200b mimics. Subsequently, RT-qPCR was performed to analyze the expression of miRNA200b and western blot analysis was used to detect the expression of WAVE3 protein. Compared with the blank control group and the mimic negative control group, the expression of miRNA200b in the miRNA200b mimic group was increased (Fig. 4A) and the protein expression levels of WAVE3 were decreased (Fig. 4B and $\mathrm{C} ; \mathrm{P}<0.001$ ). The results suggested that WAVE3 expression may be inhibited by miRNA200b.

Effects of WAVE3 inhibition by miRNA200b on cell migration. It has been previously reported that WAVE3 is associated with cell migration, and displays a negative association with the level of miRNA200b expression (31). Therefore, it was hypothesized that high levels of miRNA200b expression may inhibit cell migration (32). A Transwell assay was performed to investigate this hypothesis. Compared with the blank control group and the mimic negative control group, cell migration was decreased in the miRNA200b mimic group (Fig. 5A and $\mathrm{B} ; \mathrm{P}<0.01$ ). Therefore, the results suggest that miRNA200b inhibition of WAVE3 expression decreases ESCC cell migration.

\section{Discussion}

A number of studies have indicated the significance of WAVE3 in numerous types of cancer, including pancreatic, breast, prostate, gastric, ovarian and bladder cancer $(25,28,29,35,42,43)$. WAVE3 has been reported to participate in a variety of signaling pathways, including NF- $\mathrm{B}$ signaling pathway, p38 pathway, PI3K pathway and AKT pathway, displaying a regulatory role in cellular processes, including proliferation and migration $(20,21,24,28,35,43-45)$. In the present study, increased WAVE3 expression was observed in ESCC tissues and patient serum compared with the normal controls. The results of the immunohistochemistry assay indicated that WAVE3 was primarily expressed in the cytoplasm, and expression in cancer tissues was higher compared with non-cancerous tissues. The results were consistent with previous studies, which also 


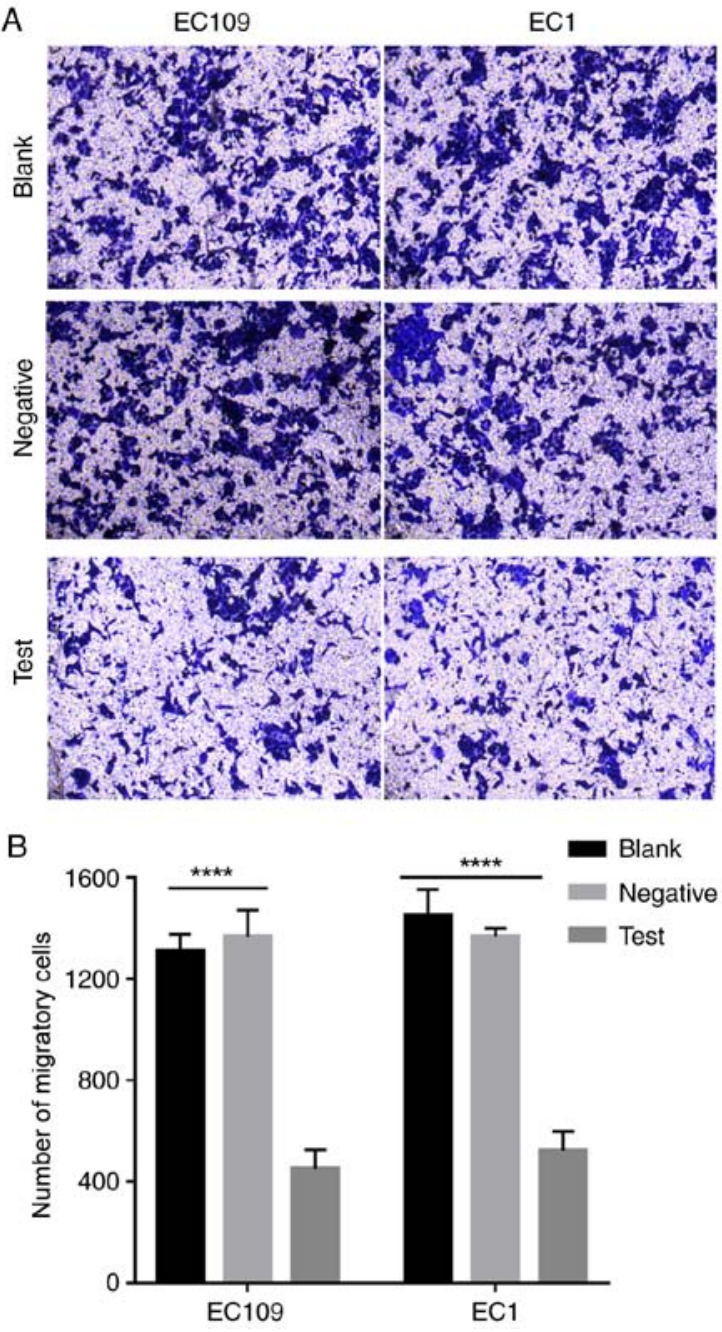

Figure 5. Cell migration evaluated using a Transwell assay. (A) EC109 and EC1 cell migration at $48 \mathrm{~h}$ according to Transwell assay (magnification, $\mathrm{x} 100$ ). (B) Comparison of the migration of cells transfected with miRNA200b mimic, mimic negative control and the blank control group in EC109 and EC1 cell lines. ${ }^{* * * * *} \mathrm{P}<0.0001$. miRNA, microRNA.

reported abnormal expression of WAVE3 in tumors, such as breast, prostate, ovarian and bladder cancer, indicating that WAVE3 expression may be associated with the development of cancer $(28,42,43,46)$. A number of studies have indicated the role of WAVE3 in cellular processes, including motility, migration, invasion and proliferation, in a number of types of cancer such as hepatocellular carcinoma, prostate cancer and colorectal cancer $(22,29,30)$. The aforementioned studies indicate that the effect of WAVE3 on cell migration occurs at the gene level and is not associated with alterations to the number of cells.

Although the diagnosis and treatment of EC has significantly improved in recent years, the 5-year survival rate remains low, and infiltration and metastasis are still the primary causes of EC-associated mortality (47). Sossey-Alaoui et al (20) indicated the upregulated WAVE3 expression was associated with poor prognosis in patients with breast cancer. Further investigation indicated that the expression of WAVE3 is closely associated with overall survival, survival rate after recurrence, mortality of patients with breast cancer, metastasis and progression (45). WAVE3 upregulation is also associated with lymph node metastasis, differentiation of pancreatic cancer cells and prognosis in patients with pancreatic cancer (25). Furthermore, WAVE3 is highly expressed in tissues of patients with colorectal cancer (30). However, in the analysis of prognostic factors, patients without lymph node metastasis or distant metastasis of other organs displayed increased WAVE3 expression levels compared with patients with poor prognosis, which is contrary to the results reported in other studies investigating breast, pancreatic and prostate cancer $(25,28,46)$. According to the analysis of ESCC clinical data conducted in the present study, positive WAVE3 expression was higher in patients at TNM stage III/IV (36.4\%) compared with TNM stage I/II (12.5\%). The positive WAVE3 expression rate in deep muscle layer and outer layer infiltration (27.7\%) was also higher compared with the submucosa and superficial layer (0\%). Additionally, WAVE3 upregulation displayed a positive association with lymph node metastasis. The results of the present study indicated that the abnormal expression of WAVE3 was associated with tumor stage, infiltration depth and lymphatic invasion. Yue et al (35) reported high expression of WAVE3 mRNA in the serum of patients with gastric cancer, and revealed that high WAVE3 expression was closely associated with lymph node metastasis, depth of tumor invasion and TNM stage of gastric cancer. Due to missing of patient clinical data on tumor invasion depth of serum samples, the association between serum levels of WAVE3 and depth of invasion were not analyzed in the present study. However, the expression of WAVE3 in serum was also positively associated with TNM stage and lymphatic invasion. The results of the present study are consistent with the previous studies that investigated breast, prostate, bladder and ovarian cancer $(37,42,43)$. According to the aforementioned data, WAVE3 may display an important role in the aggressive progression of ESCC, and may be associated with poor prognosis.

Previous studies have demonstrated that the expression of the miRNA200 family is downregulated in a number of different types of cancer, including breast, gastric and bladder cancer $(28,32,35,43)$. The present study indicated that miRNA200b was downregulated in the serum of patients with ESCC compared with healthy subjects. Considering the higher serum level of WAVE3 in patients with ESCC compared with healthy controls, it was hypothesized that miRNA200 expression was negatively associated with WAVE3 expression in patients with ESCC. The results are consistent with a previous study that indicated that WAVE3 is a direct target of miRNA200b, using a luciferase reporter assay (32). The ESCC cell lines EC109 and EC1 were transfected with a miRNA200b mimic, and the expression of WAVE3 protein and miRNA200b were determined. The results suggested that higher levels of miRNA200b and lower levels of WAVE3 protein were observed in the miRNA200b mimic group compared with the negative control group, which indicated that exogenous miRNA200b inhibits the expression of WAVE3 protein in ESCC cells. Therefore, it was hypothesized that miRNA200b downregulation may contribute to the upregulation of WAVE3 in ESCC cells; however, the underlying mechanisms require further investigation.

Previous studies have demonstrated that the expression of WAVE3 is positively correlated with tumor metastasis, such as breast, pancreatic, prostate and colon 
cancer, and that miRNA200b may inhibit the expression of WAVE3 $(20,25,32,46)$. In the present study, cells transfected with miRNA200b mimic were used to analyze cell migration. According to the Transwell assay, the number of migratory cells was significantly reduced at $48 \mathrm{~h}$ in the miRNA200b mimic group compared with the negative control group, which indicated that cell migration decreased when WAVE3 expression was downregulated. WAVE3 may serve as a novel diagnostic biomarker and therapeutic target for ESCC; however, the underlying mechanisms require further investigation. By investigating WAVE3, its altered expression in digestive system tumors and its association with microRNAs, knowledge of the role of WAVE3 in tumor cell migration may be improved.

Although the diagnostic and therapeutic strategies for malignant tumors have improved in recent years, the association between tumors and clinicopathological parameters has not yet been determined $(6,7,9)$. At present, the migration mechanism mediated by WAVE3 has not been reported. An increasing number of studies have demonstrated that WAVE3 protein expression is associated with the development and progression of tumors $(27,45,48)$. To the best of our knowledge, the present study is the first to investigate the role of WAVE3 in ESCC. Further research is required to support the use of WAVE3 as a biological indicator of tumor diagnosis and prognosis. Moreover, future studies assessing WAVE3 expression in ESCC may support the use of WAVE3 as a potential therapeutic target to reduce metastasis, improve the survival rate of patients with cancer and decrease the rate of cancer recurrence.

In conclusion, the present study indicated that WAVE3 expression was upregulated in ESCC tissues and serum, and increased levels of WAVE3 were associated with poor prognosis. Furthermore, the expression of WAVE3 was negatively associated with miRNA200b expression. miRNA200b overexpression decreased the expression of WAVE3 protein, thereby inhibiting the migration of ESCC. Therefore, the present study provided a novel insight into ESCC progression, and identified a potential diagnostic biomarker and therapeutic target for ESCC.

\section{Acknowledgements}

The authors would like to thank Professor Chunfeng Ren of the First Affiliated Hospital of Zhengzhou University, for providing laboratory support.

\section{Funding}

The present study was supported by the Henan Provincial Department of Education Key Science and Technology Project (grant no. 18A320007), the Ministry of Health and Welfare Committee (grant no. SBGJ2018013) and the Key Medical Science and Technology Project of Health Department (grant no. 201503008).

\section{Availability of data and materials}

The datasets used and/or analyzed during the current study are available from the corresponding author on reasonable request.

\section{Authors' contributions}

XL and JG performed the experiments. XL wrote the manuscript, and analyzed and interpreted the data. ZR and CX participated in performing the experiments and analysis of the data. YL designed the study and participated the revision of the manuscript. As the corresponding author, HL participated in the design of the research, and was responsible for the accuracy of all aspects of the work and the final decision to submit the article for publication. All authors read and approved the final manuscript.

\section{Ethics approval and consent to participate}

The present study was approved by the Institute Research Ethics Committee of the First Affiliated Hospital of Zhengzhou University (permit no. SS-2019-060). All patients provided written informed consent.

\section{Patient consent for publication}

Not applicable.

\section{Competing interests}

The authors declare that they have no competing interests.

\section{References}

1. Jemal A, Bray F, Center MM, Ferlay J, Ward E and Forman D: Global cancer statistics. CA Cancer J Clin 61: 69-90, 2011.

2. Liang H, Fan JH and Qiao YL: Epidemiology, etiology, and prevention of esophageal squamous cell carcinoma in China. Cancer Biol Med 14: 33-41, 2017.

3. Malhotra GK, Yanala U, Ravipati A, Follet M, Vijayakumar M and Are C: Global trends in esophageal cancer. J Surg Oncol 115: 564-579, 2017.

4. Arnold M, Soerjomataram I, Ferlay J and Forman D: Global incidence of oesophageal cancer by histological subtype in 2012 . Gut 64: 381-387, 2015.

5. Chen J, Kwong DL, Cao T, Hu Q, Zhang L, Ming X, Chen J, $\mathrm{Fu} \mathrm{L}$ and Guan X: Esophageal squamous cell carcinoma (ESCC): Advance in genomics and molecular genetics. Dis Esophagus 28: 84-89, 2015.

6. Tsukada Y, Higashi T, Shimada H, Kikuchi Y and Terahara A: The use of neoadjuvant therapy for resectable locally advanced thoracic esophageal squamous cell carcinoma in an analysis of 5016 patients from 305 designated cancer care hospitals in Japan. Int J Clin Oncol 23: 81-91, 2018.

7. Zhang L, Ma J, Han Y, Liu J, Zhou W, Hong L and Fan D: Targeted therapy in esophageal cancer. Expert Rev Gastroenterol Hepatol 10: 595-604, 2016.

8. Katada C, Muto M, Momma K, Arima M, Tajiri H, Kanamaru C Ooyanagi H, Endo H, Michida T, Hasuike N, et al: Clinical outcome after endoscopic mucosal resection for esophageal squamous cell carcinoma invading the muscularis mucosae-a multicenter retrospective cohort study. Endoscopy 39: 779-783, 2007.

9. Lin D, Ma L, Ye T, Pan Y, Shao L, Song Z, Jiang S, Chen H and Xiang J: Results of neoadjuvant therapy followed by esophagectomy for patients with locally advanced thoracic esophageal squamous cell carcinoma. J Thorac Dis 9: 318-326, 2017.

10. Fink U, Stein HJ, Bochtler H, Roder JD, Wilke HJ and Siewert JR: Neoadjuvant therapy for squamous cell esophageal carcinoma. Ann Oncol 5 (Suppl 3): S17-S26, 1994.

11. Heise JW, Heep H, Frieling T, Sarbia M, Hartmann KA and Röher HD: Expense and benefit of neoadjuvant treatment in squamous cell carcinoma of the esophagus. BMC Cancer 1: 20, 2001. 
12. Xu SY, Liu Z, Ma WJ, Sheyhidin I, Zheng ST and Lu XM: New potential biomarkers in the diagnosis of esophageal squamous cell carcinoma. Biomarkers 14: 340-346, 2009.

13. Lo YM, Tein MS, Lau TK, Haines CJ, Leung TN, Poon PM, Wainscoat JS, Johnson PJ, Chang AM and Hjelm NM: Quantitative analysis of fetal DNA in maternal plasma and serum: Implications for noninvasive prenatal diagnosis. Am J Hum Genet 62: 768-775, 1998.

14. Thrasher AJ and Burns SO: WASP: A key immunological multitasker. Nat Rev Immunol 10: 182-192, 2010.

15. Takenawa T and Suetsugu S: The WASP-WAVE protein network: Connecting the membrane to the cytoskeleton. Nat Rev Mol Cell Biol 8: 37-48, 2007.

16. Machesky LM and Insall RH: Scarl and the related Wiskott-Aldrich syndrome protein, WASP, regulate the actin cytoskeleton through the Arp2/3 complex. Curr Biol 8: 1347-1356, 1998

17. Imai K, Morio T, Zhu Y, Jin Y, Itoh S, Kajiwara M, Yata J, Mizutani S, Ochs HD and Nonoyama S: Clinical course of patients with WASP gene mutations. Blood 103: 456-464, 2004.

18. Miki H, Suetsugu S and Takenawa T: WAVE, a nove WASP-family protein involved in actin reorganization induced by Rac. EMBO J 17: 6932-6941, 1998.

19. Sossey-Alaoui K, Ranalli TA, Li X, Bakin AV and Cowell JK WAVE3 promotes cell motility and invasion through the regulation of MMP-1, MMP-3, and MMP-9 expression. Exp Cell Res 308: 135-145, 2005.

20. Sossey-Alaoui K, Li X, Ranalli TA and Cowell JK: WAVE3-mediated cell migration and lamellipodia formation are regulated downstream of phosphatidylinositol 3-kinase. J Biol Chem 280: 21748-21755, 2005.

21. Zhu Z, Chen W, Yin X, Lai J, Wang Q, Liang L, Wang W, Wang A and Zheng C: WAVE3 induces EMT and promotes migration and invasion in intrahepatic cholangiocarcinoma. Dig Dis Sci 61: 1950-1960, 2016.

22. Ji Y, Li B, Zhu Z, Guo X, He W, Fan Z and Zhang W: Overexpression of WAVE3 promotes tumor invasiveness and confers an unfavorable prognosis in human hepatocellular carcinoma. Biomed Pharmacother 69: 409-415, 2015.

23. Davuluri G, Sossey-Alaoui K and Plow E: Abstract 2702: WAVE3 regulates NF B signaling and sensitizes cancer cells to apoptosis and cell death driven by TNF. Cancer Res 73 (Suppl 8): $2702,2013$.

24. Davuluri G, Augoff K, Schiemann WP, Plow EF and Sossey-Alaoui K: WAVE3-NFאB interplay is essential for the survival and invasion of cancer cells. PLoS One 9: e110627, 2014

25. Huang S, Huang C, Chen W, Liu Y, Yin X, Lai J, Liang L, Wang Q, Wang A and Zheng C: WAVE3 promotes proliferation, migration and invasion via the AKT pathway in pancreatic cancer. Int J Oncol 53: 672-684, 2018.

26. Jaganathan S, Yue P, Paladino DC, Bogdanovic J, Huo Q and Turkson J: A functional nuclear epidermal growth factor receptor, SRC and Stat 3 heteromeric complex in pancreatic cancer cells. PLoS One 6: e19605, 2011.

27. Kulkarni S, Augoff K, Rivera L, McCue B, Khoury T, Groman A, Zhang L, Tian L and Sossey-Alaoui K: Increased expression levels of WAVE3 are associated with the progression and metastasis of triple negative breast cancer. PLoS One 7: e42895, 2012.

28. Sossey-Alaoui K, Safina A, Li X, Vaughan MM, Hicks DG, Bakin AV and Cowell JK: Down-regulation of WAVE3, a metastasis promoter gene, inhibits invasion and metastasis of breast cancer cells. Am J Pathol 170: 2112-2121, 2007.

29. Moazzam M, Ye L, Sun PH, Kynaston H and Jiang WG: Knockdown of WAVE3 impairs HGF induced migration and invasion of prostate cancer cells. Cancer Cell Int 15: 51, 2015.

30. Paterson EL, Kazenwadel J, Bert AG, Khew-Goodall Y, Ruszkiewicz A and Goodall GJ: Down-regulation of the miRNA-200 family at the invasive front of colorectal cancers with degraded basement membrane indicates EMT is involved in cancer progression. Neoplasia 15: 180-191, 2013
31. Valencia-Sanchez MA, Liu J, Hannon GJ and Parker R: Control of translation and mRNA degradation by miRNAs and siRNAs. Genes Dev 20: 515-524, 2006.

32. Sossey-Alaoui K, Bialkowska K and Plow EF: The miR200 family of microRNAs regulates WAVE3-dependent cancer cell invasion. J Biol Chem 284: 33019-33029, 2009.

33. Honor H, Ackland ML, Blick T, Lawrence MG, Clements JA, Williams ED and Thompson EW: Epithelial-mesenchymal and mesenchymal-epithelial transitions in carcinoma progression. J Cell Physiol 213: 374-383, 2007.

34. Taylor MA, Davuluri G, Parvani JG, Schiemann BJ, Wendt MK, Plow EF, Schiemann WP and Sossey-Alaoui K: Upregulated WAVE3 expression is essential for TGF- $\beta$-mediated EMT and metastasis of triple-negative breast cancer cells. Breast Cancer Res Treat 142: 341-353,2013.

35. Yue Z, Feng W, Xiangke L, Liuxing W, Qingxia F and Jianbo G: WAVE3 promotes epithelial-mesenchymal transition of gastric cancer through upregulation of Snail. Cancer Gene Ther 21: 499-506, 2014.

36. Savagner P: Leaving the neighborhood: Molecular mechanisms involved during epithelial-mesenchymal transition. Bioessays 23: 912-923, 2001.

37. Chen Y,Sun Y, Chen L, Xu X, Zhang X, Wang B, Min Land Liu W: miRNA-200c increases the sensitivity of breast cancer cells to doxorubicin through the suppression of E-cadherin-mediated PTEN/Akt signaling. Mol Med Rep 7: 1579-1584, 2013.

38. Cowherd SM: Tumor staging and grading: A primer. Methods Mol Biol 823: 1-18, 2012.

39. Livak KJ and Schmittgen TD: Analysis of relative gene expression data using real-time quantitative PCR and the 2(-Delta Delta C(T)) method. Methods 25: 402-408, 2001.

40. Grimson A, Farh KK, Johnston WK, Garrett-Engele P, Lim LP and Bartel DP: MicroRNA targeting specificity in mammals: Determinants beyond seed pairing. Mol Cell 27: 91-105, 2007.

41. Lewis BP, Shih IH, Jones-Rhoades MW, Bartel DP and Burge CB: Prediction of mammalian microRNA targets. Cell 115: 787-798, 2003.

42. Lu J, Wang SL, Wang YC, Wu YN, Yu X, Zhao WZ and Wang JH: High WAVE3 expression correlates with proliferation, migration and invasion in human ovarian cancer. Oncotarget 8: 41189-41201, 2017

43. Jin H, Xie Q, Guo X, Xu J, Wang A, Li J, Zhu J, Wu XR, Huang $\mathrm{H}$ and Huang C: $\mathrm{p} 63 \alpha$ protein up-regulates heat shock protein 70 expression via E2F1 transcription factor 1, promoting Wasf3/Wave3/MMP9 signaling and bladder cancer invasion. J Biol Chem 292: 15952-15962, 2017.

44. Sossey-Alaoui K, Li X and Cowell JK: c-Abl-mediated phosphorylation of WAVE3 is required for lamellipodia formation and cell migration. J Biol Chem 282: 26257-26265, 2007.

45. Sossey-Alaoui K: Surfing the big WAVE: Insights into the role of WAVE3 as a driving force in cancer progression and metastasis. Semin Cell Dev Biol 24: 287-297, 2013.

46. Fernando HS, Sanders AJ, Kynaston HG and Jiang WG: WAVE3 is associated with invasiveness in prostate cancer cells. Urol Oncol 28: 320-327, 2010.

47. Condeelis J and Segall JE: Intravital imaging of cell movement in tumours. Nat Rev Cancer 3: 921-930, 2003.

48. Takenawa T and Miki H: WASP and WAVE family proteins: Key molecules for rapid rearrangement of cortical actin filaments and cell movement. J Cell Sci 114: 1801-1809, 2001.

This work is licensed under a Creative Commons Attribution-NonCommercial-NoDerivatives 4.0 International (CC BY-NC-ND 4.0) License. 